\title{
Лингвистическая экспертиза в Германии
}

\author{
М. М. Мущинина \\ Университет Фрайбург \\ Heinestraße 6, 66121 Saarbrücken, Германия, E-mail: info@mushchinina.com
}

\begin{abstract}
В данной статье рассматривается лингвистическая экспертиза в судебной системе Германии. Несмотря на то, что эта сфера деятельности лингвистов существует в судебной практике Германии уже много десятилетий, роль лингвистов-экспертов в Германии ограничена лишь некоторыми традиционными областями. Эта ситуация обусловлена, в первую очередь, особыми принципами работы судов и высокой степенью структурирования источников информации, которыми судьи располагают для принятия решений, что дает им возможность во многих случаях не прибегать к помощи лингвиста. Немаловажную роль в формировании сферы деятельности лингвистов-экспертов играют и экономические факторы, в частности, система получения экспертных лицензий и гонораров. В статье приводятся примеры из двух комментариев к статье 185 Уголовного кодекса Германии (оскорбление) - источников, на которые суд может опираться при принятии решений.
\end{abstract}

Ключевые слова: судебная экспертиза, лингвистическая экспертиза, комментарии к законам.

\section{Linguistic expertise in Germany}

\author{
Mushchinina M.M. \\ University of Freiburg \\ Heinestraße 6, 66121 Saarbrücken, Germany, E-mail: info@mushchinina.com
}

\begin{abstract}
The article deals with linguistic expertise in the legal system of Germany. Despite the fact that this field of linguistic activity has existed in the judicial practice of Germany for a long time, the role of linguistic experts in Germany is limited to only some traditional areas. This situation is primarily due to the special court principles and the highly structured sources of legal information that judges use for making decisions. In many cases this enables them to analyse and evaluate linguistic issues without any help of a linguist. Furthermore, economic factors play an important role in laying out the scope of activity of linguistic experts. This concerns in particular expert licenses and expert fees. The article provides examples from two legal comments to Section 185 of the German Criminal Code (insult), which are tipical sources on which the court may rely when making decisions.
\end{abstract} Key words: forensic expertise, linguistic expertise, legal comments.

\section{1. Юридическое регулирование деятельности судебных экспертов в Германии}

Сфера деятельности судебных экспертов в Германии регулируется в области гражданского права §§ $402-414$ Гражданско-процессуального кодекса (Zivilprozessordnung), в сфере уголовного права - $\S 72$ - 93 Уголовнопроцессуального кодекса (Strafprozessordnung). В частности, кодексы регулируют порядок назначения экспертов, их 
права и обязанности, обязанности суда в ходе назначения экспертизы, функции экспертных заключений при рассмотрении дела, гонорар эксперта, а также некоторые частные случаи, в которых назначается экспертиза.

Хотя стороны могут заказать экспертизу независимо от решения суда, суд один принимает решение о рассмотрении экспертизы в качестве средства доказывания. Во многих случаях суд обязан привлечь эксперта, так как такова установившаяся судебная практика, но лишь в редких случаях это формально предусматривается например, в вопросах помещения в психиатрическую лечебницу, согласно § 280 Закона о производстве по делам семьи и добровольной юрисдикции (Gesetz über das Verfahren in Familiensachen und in den Angelegenheiten der freiwilligen Gerichtsbarkeit, FamFG). Представители сторон, прокуратура или защитники могут подать прошение о привлечении эксперта, и суд должен его удовлетворить, если нет причин для отказа. Суд может отказать в проведении экспертизы, если ситуация очевидна и не требует дополнительного разбирательства, если положение дел уже доказано или же у суда уже есть заключение эксперта. Но может быть назначена и повторная экспертиза, если есть сомнения в компетентности эксперта или в надежности и адекватности его методов, а также в том случае, если другой эксперт располагает более надежными или эффективными методами исследования.

В том случае, если в споре сторона представит свою экспертизу, заказанную частному эксперту, то это экспертное заключение будет рассматриваться не как доказательство, а как квалифицированное заявление, которое суд обязан принять во внимание. Но если суд совершенно не согласен с мнением частного эксперта, то ему недостаточно просто проигнорировать его экспертное заключение. В подобной ситуации он, вероятнее всего, назначит еще одну экспертизу, уже со своей стороны. Если первые два заключения будут различными по существу, то будет назначена третья экспертиза. В остальном же суд не обязан назначать эксперта и сам решает, нужно ли ему для принятия решения экспертное заключение или нет.

Согласно статье 404 Гражданско-процессуального кодекса, для проведения экспертизы может быть приглашен каждый, кто обладает специальными знаниями в соответствующей области и профессионально занимающийся этой областью знания - будь то в научной сфере, в сфере искусства или производства. При наличии соответствующей квалификации выступать в роли эксперта является обязанностью каждого гражданина, однако никто не может быть принужден заниматься экспертной деятельностью в ущерб своим непосредственным трудовым обязанностям.

Суд свободен в выборе эксперта, однако он, как правило, отдает предпочтение сертифицированным экспертам (§ 73 абз. 2 Уголовно-процессуального кодекса; § 404 абз. 2 Гражданско-процессуального кодекса). При назначении эксперта суд обязан объяснить эксперту его обязанности. Однако это происходит не всегда, и далеко не все эксперты понимают, что входит в сферу их компетенции. Опытный эксперт при коммуникации с судом может установить рамки, в которых он будет действовать, и прежде всего обговорить, в какой мере он может ответить на заданные ему вопросы. При этом эксперт вправе указать на неверную постановку вопроса и договориться о другой формулировке. Основной проблемой при ответе на поставленный перед экспертом вопрос является установление границы между анализом положения дел и юридическим выводом из этого анализа. Хотя этот вывод может сделать только суд, опытные эксперты часто сами его предварительно формулируют.

\section{2. Организация деятельности экспертов}

Чтобы получить статус сертифицированного эксперта, нужно подать заявление в Торгово-промышленную палату (ср., например, IHK Frankfurt 2012). Стоимость рассмотрения заявления - минимум 500 евро, однако в среднем расходы на получение статуса эксперта составляют от 1000 до 3000 евро. Срок действия лицензии - 5 лет, после чего можно подавать заявление на ее продление.

Гонорары за проведение экспертиз в Германии достаточно высоки. Они определены Законом о возмещении и компенсации в области юстиции (§ 9 Прилож. 1 абз. 1 данного закона). Для профессиональной деятельности экспертов это означает, что экспертизы особенно широко распространены в тех специальных областях, в которых суд не может принять решение, не прибегая к помощи эксперта. Очень часто решение о назначении экспертизы определяется обязанностью судьи следить за объемом судебных расходов. Поэтому судьи по возможности принимают решение без консультаций эксперта, полагаясь на свое образование и свой жизненный опыт [Steinke 1994: 16]. Так суд делает всегда, когда считает, что в состоянии самостоятельно принять компетентное решение или же получить необходимую для этого информацию. При этом суд полагается на собственную оценку своей компетентности и своих знаний.

В Германии дискуссии о жизненном опыте судьи как основе его компетентности при вынесении решений имеют давнюю историю. Этому вопросу посвящено много литературы, существуют также судебные решения о правомерности непривлечения эксперта и аргументации решения судьей лишь на основании собственного опыта. Однако в общем суды федеральных земель лишь в редчайших случаях усматривают в действиях судьи недостаточный или неверный жизненный опыт [Sommer 2002].

Как правило, экспертизы проводятся в свободной форме, не группой экспертов, а отдельными экспертами. Единых образцов для составления экспертиз или определенных формальностей при составлении экспертиз формально не существует. Однако примеры (нелингвистических) экспертиз можно найти как на страницах частных экспертов (см., например, [Kniffka 1990b]), так и в ходе курсов, проводимых Институтом экспертизы (Institut für Sachverständigenwesen), главное отделение которого находится в Кельне. Институт занимается разработкой и стандартизацией требований к назначению экспертиз и директив по проверке компетентности кандидатов в сертифицированные эксперты. При этом он оказывает поддержку организациям, заказывающим экспертизы (Палата архитекторов, Палата ремесленников, Торгово-промышленная палата и дp.) [IfS 2017]. 
В Германии существуют также сообщества экспертов, которые являются представителями их интересов. Самое старое сообщество экспертов, созданное 25 лет назад и охватывающее все сферы экспертной деятельности это „Bundesverband Deutscher Sachverständiger und Fachgutachter e.V.“ Другое крупное сообщество - Der Deutsche Gutachter und Sachverständigen Verband e.V. Сообщества предоставляют экспертам актуальную информацию о юридической основе их деятельности и являются платформой для расширения профессиональных контактов экспертов. Для потенциальных клиентов эти сообщества предлагают сервисные услуги по поиску эксперта в нужной специальной сфере и по месту жительства.

\section{3. Лингвистическая экспертиза}

В литературе, посвященной судебной лингвистике, в первую очередь уделяется внимание тем областям, которые в бо́льшей степени востребованы судами. Эти типичные сферы экспертной деятельности будут рассмотрены ниже. Экспертизы по оценке семантики и прагматики языковой коммуникации заказываются значительно реже [Kniffka 1990a; Kniffka 1981; Stetter 1990; Ritter 1990].

\section{1. Типичные сферы деятельности лингвистов-экспертов}

В большинстве случаев немецкие судьи считают себя достаточно компетентными в лингвистической области и ставят знак равенства между высоким уровнем владения родным языком и способностью оценить коммуникативную ситуацию как специалист-лингвист. Отчасти такая оценка судьями своей компетентности связана с традиционной в юридической сфере дискуссией о тесной связи языка и права, а также о сложности, которую представляет юридический язык для неюристов. И хотя в оценке языка повседневного общения юристы не обладают теми же исключительными знаниями, как в областях специального юридического знания, они распространяют сферу своей компетентности и на язык повседневного общения, с нежеланием допуская в сферу своей деятельности лингвистов. Юридическое образование в Германии в значительной мере сосредоточено на овладении методами поиска информации и принципами (юридической) логики. Высокая компетентность немецких судей в этих сферах является для них достаточным основанием для принятия самостоятельных решений и в сфере языка повседневного общения - например, при оценке прагматики языковых ситуаций.

В каких же случаях проводятся экспертизы в лингвистической области? Рассмотрим самые известные из сфер деятельности лингвистов-экспертов.

Чаще всего проводятся экспертизы для установления авторства. Именно эта сфера деятельности лингвистовэкспертов известна в юридических кругах, то есть среди служащих следственных комитетов, судей и адвокатов [Wirth 2013]. Часто судебная лингвистика отождествляется именно с этим видом экспертиз. Такие экспертизы могут касаться как анализа отдельного текста, так и установления совместного или различного от других текстов авторства ([Fobbe 2017]; подробно [Dern 2009]). В первом случае вопрос заключается в установлении каких-либо социальных особенностей автора (происхождение, социальный статус, образование, возраст и проч.). Во втором случае проводится сравнительный анализ нескольких текстов. В обоих случаях анализ текстов проводится с учетом типичных особенностей типа текста, который является предметом исследования. Например, для писем с целью шантажа типичны отсутствие заключения, коллективное обращение, а также определенные - известные эксперту сокращения [Fobbe, 2017]. Критерии исследования по установлению авторства, так же как и принципы и возможности анализа стиля текста, известны не только в Германии, но и любой другой стране. В немецкой научной литературе можно найти критические замечания, касающиеся качественной стороны методов анализа стиля и установления авторства. В частности, указывается на ненадежность этих методов, их зависимость от имеющегося объема текстов, который должен быть представлен определенным минимумом, а также на зависимость методов анализа от качеств анализируемого текста. Так, качественный анализ зачастую определяется индивидуальными особенностями текста, что создает замкнутый круг: критерии качественного анализа текста устанавливаются в зависимости от индивидуальных особенностей текста, и эти же особенности исследуются по установленным на их основе критериям [Ammer et al. 2013; Fobbe 2017].

В последнее время все более широкое распространение получают экспертизы, устанавливающие происхождения лица. Эта сфера деятельности судебных экспертов значительно расширилась в связи с миграционной политикой последних лет. Как в судебной, так и в административной области она опирается на систему LADO (Language Analysis for the Determination of Origin), применяющуюся с 1990-х годов. Лингвисты устанавливают происхождение не только в контексте судебного разбирательства. Они оказывают поддержку миграционным службам в тех случаях, когда беженец подает заявку на предоставление ему права находиться на территории Германии и при этом не может (или по какой-либо причине не хочет) указать страну своего происхождения. Методы проведения экспертиз по установлению происхождения часто являются объектом обсуждения и критики. Например, в литературе указывается на тот факт, что при определении происхождения в недостаточной степени учитывается возможность мультикультурной и мультиязычной среды, что усложняет анализ. Кроме того, для аргументированного заключения о происхождении лица необходима подготовленная сравнительная база о предполагаемой стране или регионе происхождения [Fobbe 2017]. Однако такие сравнительные базы существуют далеко не для всех регионов.

В связи с тем, что спектр языков, на которых говорят мигранты, очень широк и для многих языков и диалектов не существует соответствующих лингвистических экспертов, зачастую экспертизы для этих языков производятся не лингвистами-экспертами, а переводчиками или даже другими носителями языка, не имеющими специального лингвистического образования [Ammer et al. 2013]. Особенно это касается языков и диалектов беженцев из Африки. 
К сфере деятельности немецких лингвистов-экспертов относятся и все другие известные виды экспертиз, как то: экспертизы по установлению оригинальности коммерческих обозначений и по исследованию степени смешения противопоставленных обозначений [Parádi 2005], фоноскопические, почерковедческие и другие экспертизы [Grewendorf 1992].

\section{2. Юристы в качестве экспертов}

В общей сложности лингвистические экспертизы в Германии производятся достаточно редко. В большинстве случаев они заказываются сторонами заранее частным образом - частными лицами, юридическими конторами или фирмами, которые хотят установить, имеет ли смысл подавать иск. Впоследствии эти экспертизы остаются в материалах дела. В судах не ведется отдельной картотеки по экспертизам, поэтому ту или иную экспертизу можно найти только в том случае, если знать, для какого процесса было составлено экспертное заключение.

Что касается экспертных заключений о конкретных формулировках и языковой прагматике, то, как уже было сказано выше, в этом случае действует принцип приоритетной оценки языковых ситуаций судом. При этом судьи опираются на уже имеющуюся судебную практику и выносят решение в соответствии с ней. Основным источником информации при этом судьям служат комментарии. Чтобы продемонстрировать, на какую информацию опираются судьи и как они на основании собственного языкового опыта и комментариев приходят к оценке языковой ситуации, приведу пример принципов классификации языковой ситуации как «оскорбление» на основании юридического комментария. В частности, речь пойдет о языковых действиях, подпадающих под § 185 Уголовного кодекса Германии - оскорбление чести и достоинства. Мера наказания за оскорбление - до года лишения свободы или денежный штраф, при оскорблении с нападением - до двух лет или денежный штраф. В качестве примера я продемонстрирую два комментария по вопросу об оскорблении: комментарий по уголовному праву под редакцией Бернда фон Хайнчеля-Хайнегга (автор раздела Бриан Валериус, в дальнейшем Heintschel-Heinegg, 2018) и Мюнхенский комментарий (авторы раздела Кристиан Пегель и Юрген Регге, в дальнейшем МӥКо, 2017).

\section{3. Отражение судебной практики по делам об оскорблении в комментариях}

Heintschel-Heinegg (2018) и МüКо (2017) предоставляют типичный обзор необходимых сведений о понятиях оскорбления чести и достоинства, субъектах этого понятия, о систематике преступлений, квалифицируемых как оскорбление и о содержании речевого и коммуникативного действия, которое может подпадать под § 185 [Heintschel-Heinegg 2018; МüКо 2017]. В частности, оскорблению могут подвергаться как физические лица, так и группы лиц, если они выполняют определенную признанную, общественную или экономическую задачу, или несут в себе социальную функцию и могут представлять общее мнение или волю. Это условие выполняется, например, для юридиче [ких лиц, корпораций, обществ и ассоциаций, если они объединены собирательным названием, политических партий, фракций и т. д. В последнем случае речь идет о коллективном оскорблении [Heintschel-Heinegg 2018]. Как оскорбление могут быть квалифицированы, например, высказывания, направленные против «немецких врачей», антитеррористических отрядов полиции, «всех находящихся на службе солдат», «духовных лиц христианских религий», «немецких евреев». По этому принципу как оскорбление конкретного солдата будет квалифицировано высказывание, что «все немецкие солдаты убийцы». То же касается этнических, расовых или физических признаков. Впрочем, судьи скорее склоняются к тому, чтобы по возможности редко прибегать к квалификации ситуации как коллективного оскорбления. В частности, не расцениваются как коллективное оскорбление высказывания, направленные против всех полицейских вообще, женщин, людей с высшим образованием, католиков, протестантов и др.

Комментарии подробно раскрывают возможную внешнюю (языковую) форму оскорбления. Так, оскорбление не обязательно должно происходить в неприличной форме, но оно должно затрагивать по существу честь и достоинство лица. В комментариях рассматривается понятие чести и разных его аспектов: фактическое и нормативное понятие чести (личная, социальная, межперсональная, функциональная). Оскорбление в комментарии отграничивается от бестактности и невежливого обращения и иллюстрируется примерами [Heintschel-Heinegg 2018].

Комментарии объясняют, что должен учитывать суд при трактовке высказывания как оскорбления. В частности, не существует высказываний, которые могут независимо от контекста трактоваться как оскорбление. Суд должен учитывать контекст и обстоятельства высказывания (тон, культурные, региональные, социальные особенности, средство коммуникации). Таким образом, при определенных обстоятельствах и косвенный намек может быть признан оскорблением. При конкретных обстоятельствах оскорблением может быть признано обращение на «ты», в другой же ситуации оно будет расценено как невежливое обращение. Учитывается и так называемый «общий горизонт реципиента» - понимание ситуации «средним» реципиентом, - и не учитывается понимание высказывания сторонами судебного разбирательства [Heintschel-Heinegg 2018].

Приведу пару примеров тех случаев, которые были квалифицированы судом как оскорбление: «младофашист» в контексте национал-социалистической идеологии, а также утверждение о том, что кто-либо «все еще нацист», «палачи» (по отношению к солдату), «Вulle» (обращение к полицейскому), запрет заходить в ресторан без явной причины, «террористическое решение» (о судебном решении), обозначение отрядов спецназа «группой киллеров», обвинение «в поддержке террористов», объявление в региональной газете типа «крошка Микаэла, с удовольствием тебя побалует» с указанием точного адреса и номера телефона [Heintschel-Heinegg 2018; MüKo 2017; Damm \& Rehbock 2008].

Высказывание не было признано оскорблением, например, в следующих случаях: «дед», «старик» (обращение к пожилому человеку), «главный лесничий» (обращение к сотруднику дорожной полиции), вульгарные выражения, присутствующие в некоторых диалектах [Heintschel-Heinegg 2018]. 
Не были классифицированы как оскорбления метафорические наименования, такие как: «синдикат живодеров» или «сборище плутов» (как обозначение участников экономических преступлений), «левый радикал» или «коммуняка» (кандидат на официальный пост) [Damm \& Rehbock 2008].

Наряду с этим Федеральный конституционный суд отменил многие решения о классификации высказываний как оскорблений в тех случаях, когда он счел, что сказанное подпадает под действие права на свободу мнения (ст. 5 абз. 1 Основного закона) и классифицируется как оценочное суждение. Таким образом, полемические формулировки рассматриваются и в рамках конституции (Основного закона), а не только уголовного права [Damm \& Rehbock 2008].

Также статья об оскорблении не применяется и в тех случаях, когда характеристика лица преподносится в какой-либо художественной форме, независимо от степени художественной ценности [МӥКо 2017]. В частности, в 2016 году президент Турции Эрдоган обратился в суд Германии с иском против немецкого журналиста и телеведущего Яна Бемермана, прочитавшего по второму государственному каналу немецкого телевидения стихотворение про президента Эрдогана, в котором последнему приписываются всевозможные пороки, в основном сексуального характера - например, использование детской порнографии и содомия. При судебном разбирательстве вопрос заключался в том, является ли данное стихотворение оскорблением или же оно допустимо как художественная сатира. Как сатирическое высказывание мнения стихотворение было бы правомерно по ст. 5 абз. 1 Основного закона (Grundgesetz), как художественная сатира оно тоже было бы правомерно по ст. 5 абз. 3 Основного закона. В то же время, оно могло противоречить статье 1 Основного закона, которая гласит, что достоинство человека неприкосновенно. Телевизионный канал заказал экспертизу, но не лингвисту-эксперту, а адвокатской конторе, которая пришла к выводу, что проанализированные «речевые пассажи, включая «оскорбительное стихотворение» в правовом отношении допустимы и не могут подвергаться уголовному наказанию». В конце концов, по статье 185 - оскорбление - дело было закрыто. Суд признал стихотворение сатирой по ст. 5 абз. 3 Основного закона, однако запретил бо́льшую часть его в связи с «расистским уклоном», «религиозными оскорблениями» и «намеками сексуального характера». В ответ на это обе стороны подали апелляцию - соответственно с целью полного разрешения стихотворения или полного его запрещения. В обоих случаях апелляция не имела успеха.

\section{Заключение}

Цель данной статьи заключалась в том, чтобы продемонстрировать, что практика лингвистической экспертизы в Германии в значительной мере определяется структурой и возможностями судебной системы. Как было показано на примере двух комментариев к Уголовному кодексу Германии, при принятии решений судьи, исходя из предоставляемой комментариями информации и опираясь на судебную практику и свой жизненный опыт, устанавливают, насколько им необходима экспертиза лингвиста-эксперта. В случаях, касающихся оценки семантики и прагматики языковой ситуации, судьи, как правило, считают себя достаточно компетентными для принятия решения о том, является ли языковое действие допустимым или нет, по какой юридической норме оно может быть квалифицировано и подлежит ли оно наказанию. Поэтому такие лингвистические экспертизы в Германии достаточно редки. Лингвистическая экспертиза проводится лишь в тех случаях, когда суду необходима информация, которую он не может получить, опираясь на комментарии и свой языковой опыт. В значительной степени деятельность экспертов определяется и судебными расходами, за величиной которых судьи обязаны следить.

\section{References}

1. Ammer, M., Busch, B., Dorn, N., Rienzner, M., Santner-Wolfartsberger, A., Schicho, W., Seidlhofer, B., Spitzl, K. (2013). Ein umstrittenes Beweismittel: Sprachanalyse als Instrument der Herkunftsbestimmung im Asylverfahren. Juridikum, 3 (in German).

2. Damm, R., Rehbock, K. (2008). Widerruf, Unterlassung und Schadensersatz in den Medien. München (in German)

3. Dern, Ch. (2009). Autorenerkennung: Theorie und Praxis der linguistischen Tatschreibenanalyse. Stuttgart (in German)

4. Fobbe, E. (2017). Forensische Linguistik. In: Felder, Ekkehard; Vogel, F. (Ed.). Handbuch Sprache im Recht. Berlin (in German)

5. Grewendorf, G. (1992). Rechtskultur als Sprachkultur. Der sprachanalytische Sachverstand im Recht. Rechtskultur als Sprachkultur. Zur forensischen Funktion der Sprachanalyse. Frankfurt a. M. (in German)

6. Heintschel-Heinegg, von B. (2018). Strafgesetzbuch. 37 Edition, München (in German)

7. Kniffka, H. (1981). Der Linguist als Gutachter bei Gericht. In: Peuser, G., Winter, S. (Eds.). Angewandte Sprachwissenschaft: Grundfragen, Berichte, Methoden. Festschrift für Günter Kandler. Bonn (in German)

8. Kniffka, H. (1990a). Einleitung: Forensische Linguistik. In: Kniffka, H. (Ed.). Texte zu Theorie und Praxis forensischer Linguistik. Tübingen (in German)

9. Kniffka, H. (1990b). Alles ist Tatfrage des Einzelfalls - Oder: Herr X. bzw. seine Konkubine. In: Kniffka, H. (Ed.). Texte zu Theorie und Praxis forensischer Linguistik. Tübingen (in German)

10. MüKo StGB. (2017). Münchener Kommentar zum Strafgesetzbuch. München: C.H. Beck (in German)

11. Parádi, Zs. (2005). Zum Verwechseln unähnlich. Ein sprachwissenschaftlicher Beitrag zur Argumentation in Markenrechtsurteilen. In: Lerch, K. D. (Ed.). Recht verhandeln. Argumentieren, Begründen und Entscheiden im Diskurs des Rechts. Berlin, New York (in German)

12. Ritter, Ch. (1990). Sprachexpertisen im Zivilprozess. In: Kniffka, H. (Ed.). Texte zu Theorie und Praxis forensischer Linguistik. Tübingen (in German) 
13. Sommer, Ulr. (2002). Lebenserfahrung - Gedanken über ein Kriterium richterlicher Beweiswürdigung. In: Hanack, E.-W. et al. (Ed.). Festschrift für Peter Riess zum 70. Geburtstag am 4. Juni 2002. Berlin, New York (in German)

14. Steinke, W. (1994). Der Beweiswert forensischer Gutachten. NStZ (in German)

15. Stetter, Ch. (1990). Zum juristischen Gebrauch linguistischer Kategorien. In: Kniffka, H. (Ed.). Texte zu Theorie und Praxis forensischer Linguistik. Tübingen (in German)

16. Wirth, I. (2013). Kriminalistik-Lexikon. München (in German)

17. IHK Frankfurt. (2012). IHK Frankfurt. Sachverständigenordnung. Vorschriften der Industrie- und Handelskammer Frankfurt am Main uber die offentliche Bestellung und Vereidigung von Sachverständigen vom 27.06.2012, gemäß §36 Gewerbeordnung. Available from: https://www.frankfurt-main.ihk.de/imperia/md/content/pdf/recht/sachverst_ndigenordnung.pdf/ (in German)

18. IfS. (2017). Institut für Sachverständigenwesen e. V. Empfehlungen zur Erstellung eines Gutachtens vom $4 / 2017$. Available from: https://www.ifsforum.de/fileadmin/user_upload/Merkblatt_Gutachtenaufbau2017.pdf (in German).

\section{Citation:}

Мущинина М.М. Лингвистическая экспертиза в Германии. // Юрислингвистика. - 2019. - 11. - 33-38.

Mushchinina, M.M. (2019). Linguistic expertise in Germany. Legal Linguistics, 11, 33-38.

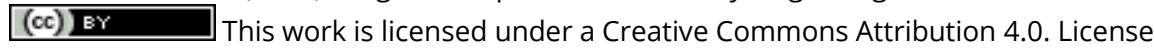

